Arq. Bras. Med. Vet. Zootec., v.69, n.1, p.165-172, 2017

\title{
Glicerina bruta associada à ureia na terminação de bovinos: consumo, desempenho e características da carne
}

[Glycerin associated with urea in finishing beef cattle: performance and meat characteristics]

\author{
A.P. D'Aurea, J.M.B. Ezequiel, E.M.O. D'Aurea, V.C. Santos, V.R. Fávaro, \\ A.C. Homem Júnior, M.T.C. Almeida, H.L. Perez
}

Faculdade de Ciências Agrárias e Veterinárias - FCAV-Unesp - Jaboticabal, SP

\section{RESUMO}

Objetivou-se nesta pesquisa avaliar os efeitos da combinação de glicerina bruta e ureia sobre o consumo, o desempenho produtivo e as características da carne de bovinos da raça Nelore. O estudo foi conduzido no confinamento do Setor de Digestibilidade, pertencente à Faculdade de Ciências Agrárias e Veterinárias-FCAV/Unesp, Câmpus de Jaboticabal. Para tal, 28 novilhas, da raça Nelore $(\mathrm{n}=28$, com aproximadamente 20 meses de idade, $278 \pm 5,6 \mathrm{~kg}$ ), foram aleatoriamente distribuídas em quatro tratamentos utilizando-se de delineamento inteiramente ao acaso. Quatro dietas com energia metabolizável e proteína bruta semelhantes foram formuladas utilizando-se a proporção volumoso:concentrado de 30:70. O volumoso empregado foi silagem de milho, e os concentrados foram compostos por milho grão moído, casca de soja, farelo de girassol, e a utilização ou não de acordo com o tratamento de glicerina e ureia. A introdução da glicerina e da ureia na dieta foi fixada, respectivamente, em 10 e $1 \%$ de inclusão na matéria seca da dieta. Os tratamentos foram: $\mathrm{C}=$ controle sem glicerina e ureia; $\mathrm{U}=1 \%$ de ureia na matéria seca; $\mathrm{G} 10=10 \%$ de glicerina na matéria seca; GU10 $=10 \%$ de glicerina e $1 \%$ de ureia na matéria seca. A introdução de $10 \%$ de glicerina bruta, com ou sem a presença de ureia, não modificou o consumo, tampouco nenhuma variável do desempenho produtivo $(\mathrm{P}>0,05)$. As características físico-químicas da carne, bem como o perfil de ácidos graxos, também não foram modificadas. O desempenho dos animais e as características da carne foram satisfatórios e dentro dos padrões esperados encontrados na literatura. Assim, a associação de glicerina com ureia pode ser uma estratégia viável em sistemas de produção de bovinos confinados.

Palavras-chave: biodiesel, glicerol, NNP, qualidade da carne

\begin{abstract}
The aim of this research was to investigate the effect of glycerol with urea, on the consumption and nutritional performance of Nelore cattle. The work was conducted within the confines of the digestibility sector, belonging to the Faculdade de Ciências Agrárias e Veterinária - FCAV/Unesp campus Jaboticabal. Heifers, Nellore, with approximately 20 months of age with an average body weight of $278 \mathrm{~kg}$ were allotted to four treatments using a completely randomized design. Four diets with similar metabolizable energy and crude protein were formulated using the forage: concentrate ratio of 30:70. The roughage used was corn silage. The concentrates used were composed of corn, soybean hulls, sunflower meal, and the use or not of glycerin and urea in accordance with the treatment. The introduction of glycerin and urea in the diet was fixed respectively at 10 and $1 \%$ inclusion in the diet dry matter, based on recommendations found in the literature for cattle confinados. The treatments were: $C=$ control without glycerin and urea, $U=1 \%$ urea in dry matter; $G 10=10 \%$ glycerin dry matter; $G U 10=$ $10 \%$ glycerin and $1 \%$ urea in dry matter. The diets were not different $(P>0.05)$ in regards to performance of animals or meat characteristics, so the use of glycerin or glycerine association with urea did not alter the growth traits of Nelore heifers finished in confinement. Thus the association of glycerol with urea may be a viable strategy in the production of cattle feedlot systems.
\end{abstract}

Keywords: biodiesel, glycerol, NNP, meat production

Recebido em 25 de novembro de 2015

Aceito em 9 de agosto de 2016

E-mail: andredaurea@gmail.com 


\section{INTRODUÇÃO}

A glicerina corresponde a aproximadamente $10 \%$ da massa total resultante no processo de produção do biodiesel (Gonçalves, 2008), consequentemente o aumento da produção de biodiesel aumenta a oferta de glicerina. O mercado da glicerina é estável e novas alternativas são necessárias para sua utilização.

Para Donkin (2008), a glicerina surge como um novo milho na alimentação de ruminantes, substituindo parcial ou totalmente alimentos energéticos tradicionais, podendo, assim, ser uma alternativa para redução nos custos em sistemas de produção de animais confinados, além de dar destino ambientalmente correto a esse produto. Relata ainda a utilização de 5 a $8 \%$ de glicerina na matéria seca da dieta como artifício preventivo de distúrbios metabólicos em vacas leiteiras de alta produção. De acordo com o mesmo autor, a glicerina pode ser incluída até $15 \%$ na matéria seca da dieta, sem interferir na ingestão de alimentos nem na produção animal.

Parte do nitrogênio da dieta, seja de origem não proteica ou proteína verdadeira, é utilizada pelos micro-organismos do rúmen e transformada em proteína de boa qualidade. A capacidade das bactérias de utilizarem o nitrogênio não proteico (NNP) depende da quantidade e da taxa de degradação da energia fornecida ao animal e da capacidade de crescimento da população de micro-organismos, limitado pela energia. Como a glicerina é um ingrediente exclusivamente energético, a sua inclusão em dietas deve ser compensada por uma inclusão de ingredientes protéicos, e a ureia é um produto exclusivamente proteico. A glicerina é uma fonte de liberação rápida de energia, portanto sua associação com a ureia pode ter efeitos positivos no crescimento da população microbiana.

Schoröder e Südekum (1999) avaliaram in vivo e in vitro a adição de 10,15 ou $20 \%$ de glicerina na matéria seca da dieta de bovinos, em dietas com alto e baixo amido e glicerina com diferentes purezas, e concluíram que a inclusão de $10 \%$ de glicerina de média pureza na matéria seca da dieta não afetou a ingestão de água, a degradação ruminal e a digestibilidade dos nutrientes. A glicerina de média pureza utilizada por Schoröder e Südekum (1999) possuía 11\% de água, 85,3\% de glicerol e 0,04\% de metanol, sendo similar à glicerina do presente estudo.

Recentes trabalhos apontam para a concentração de $10 \%$ de inclusão de glicerina na matéria seca da dieta como sendo um valor interessante do ponto de vista nutricional, não alterando o desempenho e as características da carne de animais confinados, e podendo até melhorar a eficiência de ganho (Pyatt et al., 2007; Parsons et al., 2009; Mach et al., 2009).

Segundo Valadares Filho et al. (2006), 1\% de ureia na matéria seca da dieta de zebuínos confinados é o suficiente para atender as condições ruminais necessárias para o bom desempenho em confinamento.

Assim, objetivou-se avaliar dietas contendo ureia e glicerina na terminação de novilhas da raça Nelore quanto ao desempenho e às características da carne.

\section{MATERIAL E MÉTODOS}

O experimento foi conduzido no confinamento do Setor de Digestibilidade pertencente ao Departamento de Zootecnia da Faculdade de Ciências Agrárias e Veterinárias, Unesp, Câmpus de Jaboticabal, de acordo com os princípios éticos na experimentação animal (protocolo $\mathrm{n}^{\circ}$ 027608/12) determinados pelo Conselho de Ética em Experimentação Animal da referida instituição.

Os animais foram alojados em baias de $14 \mathrm{~m}^{2}$, com piso concentrado, parcialmente cobertas e providas de bebedouros e comedouros individuais.

Foram distribuídas em quatro tratamentos, utilizando-se de delineamento inteiramente ao acaso, 28 novilhas, da raça Nelore, com aproximadamente 20 meses de idade e peso corporal médio de $278 \pm 5,6 \mathrm{~kg}$.

As dietas com energia metabolizável e proteína bruta semelhantes foram formuladas utilizandose relação volumoso:concentrado de 30:70. O volumoso empregado foi silagem de milho, e os concentrados foram compostos por milho grão moído, casca de soja, farelo de girassol e a utilização ou não, de acordo com o tratamento, de glicerina e ureia. Os tratamentos foram: 
$\mathrm{C}=$ controle sem glicerina e ureia; $\mathrm{U}=1 \% \mathrm{de}$ ureia na matéria seca; $\mathrm{G} 10=10 \%$ de glicerina matéria seca; GU10 $=10 \%$ de glicerina e $1 \%$ de ureia na matéria seca. As dietas experimentais são apresentadas na Tab. 1.

A proporção volumoso:concentrado foi de 30:70, e as dietas experimentais foram formuladas para ganho de $1,2 \mathrm{~kg} / \mathrm{dia}$, de acordo com Valadares Filho et al. (2006).

A glicerina utilizada foi proveniente da empresa Caramuru Alimentos S/A, obtida por catálise homogênea, por meio do processo de transesterificação do óleo de soja com metanol, sendo metilato de sódio o catalisador utilizado na reação, com as seguintes características: glicerol $84,4 \%$; umidade $8,8 \%$; sais $6,08 \%(99 \% \mathrm{NaCl})$; metanol $<0,01 \%$; MONG (material orgânico não glicerol) $0,72 \%$. Pelas especificações apresentadas pelo fabricante, essa glicerina é denominada comercialmente de glicerina "loura".

Toda glicerina utilizada no experimento pertencia ao mesmo lote de fabricação, sendo transportada e armazenada em tambores plásticos de cor escura, com capacidade para 200 litros. A glicerina foi homogeneizada diariamente antes da retirada para o fornecimento aos animais, com a finalidade de evitar possíveis separações de fase do produto.

O período total de confinamento foi de 100 dias, sendo os primeiros 28 dias destinados à adaptação dos animais ao manejo, às instalações e à dieta. Os animais foram pesados no início da adaptação, para a divisão deles dentro dos tratamentos, no início do período de avaliação, bem como ao final, sempre após jejum alimentar de 14 horas, para acompanhamento da evolução do peso e do ganho de peso diário. Foi determinado o ganho médio de peso, a conversão alimentar e o consumo de matéria seca.

Os animais foram alimentados duas vezes ao dia na mesma proporção, às oito e às $17 \mathrm{~h}$. $\mathrm{O}$ volumoso, o concentrado e a glicerina bruta foram pesados separadamente, misturados e fornecidos no momento da alimentação. Foram permitidos até $10 \%$ de sobras, as quais eram pesadas e amostradas diariamente antes da alimentação matinal.

Tabela 1. Porcentagem dos ingredientes e estimativa da composição bromatológica dos tratamentos experimentais (\% MS)

\begin{tabular}{|c|c|c|c|c|}
\hline \multirow{2}{*}{ Ingredientes } & \multicolumn{4}{|c|}{ Tratamentos } \\
\hline & $\mathrm{C}$ & $\mathrm{U}$ & G10 & GU10 \\
\hline Silagem de milho & 30 & 30 & 30 & 30 \\
\hline Milho & 27 & 40 & 20 & 34 \\
\hline Casca de soja & 24 & 24 & 14 & 14 \\
\hline Farelo de girassol & 18 & 4 & 25 & 10 \\
\hline Glicerina bruta & & & 10 & 10 \\
\hline Ureia & & 1 & & 1 \\
\hline Suplemento mineral $* *$ & 1 & 1 & 1 & 1 \\
\hline Nutriente & \multicolumn{4}{|c|}{ Composição estimada } \\
\hline $\mathrm{PB}(\%)$ & 12,80 & 12,93 & 12,96 & 12,91 \\
\hline $\mathrm{EM}(\mathrm{Mcal} / \mathrm{kg}) *$ & 2,75 & 2,83 & 2,73 & 2,82 \\
\hline $\mathrm{FDN}(\%)$ & 43,93 & 37,88 & 39,50 & 33,03 \\
\hline FDA $(\%)$ & 29,20 & 24,56 & 25,72 & 20,75 \\
\hline $\operatorname{HEM}(\%)$ & 14,73 & 13,32 & 13,78 & 12,28 \\
\hline $\mathrm{EE}(\%)$ & 2,66 & 3,06 & 2,30 & 2,73 \\
\hline
\end{tabular}

$\mathrm{C}=$ tratamento controle, $\mathrm{G} 10=$ tratamento com $10 \%$ de glicerina na MS, $\mathrm{U}=$ tratamento com $1 \%$ de ureia na MS, $\mathrm{GU}=$ tratamento com 10\% de glicerina e $1 \%$ de ureia na MS. $\% \mathrm{MS}=\%$ de matéria seca, $\mathrm{PB}=$ proteína bruta, $\mathrm{EE}=$ extrato etéreo, $\mathrm{FDN}=$ fibra em detergente neutro, FDA = fibra em detergente ácido, $\mathrm{HEM}=$ hemicelulose, $\mathrm{EM}=$ energia metabolizável. * Valores tabelados. ** $\mathrm{P}=40 \mathrm{~g} / \mathrm{kg} ; \mathrm{Ca}=80 \mathrm{~g} / \mathrm{kg} ; \mathrm{Na}=195 \mathrm{~g} / \mathrm{kg} ; \mathrm{Cl}=300 \mathrm{~g} / \mathrm{kg} ; \mathrm{Mg}=5 \mathrm{~g} / \mathrm{kg} ; \mathrm{S}$ $=26 \mathrm{~g} / \mathrm{kg} ; \mathrm{Zn}=2 \mathrm{~g} / \mathrm{kg} ; \mathrm{Cu}=1 \mathrm{~g} / \mathrm{kg} ; \mathrm{Mn}=0,5 \mathrm{~g} / \mathrm{kg} ; \mathrm{Co}=0,1 \mathrm{~g} / \mathrm{kg} ; \mathrm{I}=0,1 \mathrm{~g} / \mathrm{kg} ; \mathrm{Se}=5 \mathrm{mg} / \mathrm{kg} \mathrm{e} \mathrm{F}=0,4 \mathrm{~g} / \mathrm{kg}$. 
Ao final dos 100 dias de confinamento, os animais foram submetidos a jejum de sólidos de 14 horas e posteriormente levados ao frigorífico para o abate. $\mathrm{O}$ abate seguiu os procedimentos de atordoamento por concussão cerebral, utilizandose pistola de ar comprimido e posterior sangria. Obteve-se o peso de carcaça após um período de 24 horas, em câmara fria, na temperatura de $5^{\circ} \mathrm{C}$. Os rendimentos da carcaça foram determinados em relação ao peso vivo.

Após 24 horas de resfriamento, as carcaças atingiram temperatura interna média de $5,8^{\circ} \mathrm{C}$ e pH 5,7 no longuíssimo.

Foi realizado um corte transversal entre a $12 \mathrm{a}$ e 13a costelas, de maneira a expor o músculo longuíssimo, para as medidas de área de olho de lombo e da espessura de gordura de cobertura.

A espessura de gordura foi mensurada no terceiro quarto do músculo a partir da coluna vertebral, perpendicularmente ao músculo longuíssimo, com uso de um paquímetro digital (Tullio, 2004).

Em seguida, foi desenhada a área em papel vegetal e, por meio do sistema de análise de imagem Delta-T Devices, foi determinada a área de olho de lombo.

Uma porção do longuíssimo extraída da amostra foi embalada, identificada e levada para o congelador, sendo posteriormente utilizada para avaliação das características da carne no Laboratório de Tecnologia de Produtos de Origem Animal da FCAV/Unesp, Jaboticabal.

Oportunamente, os bifes foram descongelados a $3,5 \pm 0,5^{\circ} \mathrm{C}$, identificados, pesados em balança semianalítica e colocados em grelha sobreposta automática. Foi utilizado um termômetro digital para controle da temperatura interna em cada amostra. Ao atingir a temperatura interna de $71^{\circ} \mathrm{C}$, seguida de resfriamento em temperatura ambiente, as amostras foram pesadas e, por meio da diferença dos pesos inicial e final, calculou-se a perda de peso por cozimento, segundo Honikel (1998).

Para determinação da capacidade de retenção de água (CRA), 2g da amostra foram pesados e submetidos a uma pressão de $10 \mathrm{~kg}$ por cinco minutos. Após este tempo, a amostra foi novamente pesada e, por meio da diferença de peso, foi determinada a CRA, segundo Hamm (1960).

Para determinação da força de cisalhamento, as amostras foram cortadas em cilindros de $1,27 \mathrm{~cm}$ de diâmetro, analisadas por meio do texturômetro TA XT-Plus Texture Analyser 2i, Stable Micro System (UK), equipado com conjunto de lâmina Warner-Bratzler, o qual promoveu força necessária para cisalhar a amostra, em kgf/ $\mathrm{cm}^{2}$ (Corte et al., 1979).

Os teores de colesterol da carne foram determinados conforme metodologias descritas por Al Hasani et al. (1993).

Para determinação do perfil de ácidos graxos, foi utilizada metodologia de extração adaptada de Bligh e Dyer (1959) e de determinação por cromatografia gasosa. A extração da gordura foi realizada com uma mistura de clorofórmiometanol. Cerca de $3 \mathrm{~g}$ de amostra, anteriormente liofilizada, foram transferidos para um Erlenmeyer com capacidade para $125 \mathrm{~mL}$, onde foram adicionados $10 \mathrm{~mL}$ de clorofórmio, $20 \mathrm{~mL}$ de etanol e $8 \mathrm{~mL}$ de água destilada. Os frascos foram agitados por 30 minutos em mesa agitadora. Após a agitação, foram adicionados $10 \mathrm{~mL}$ de clorofórmio e $10 \mathrm{~mL}$ de sulfato de sódio a $1,5 \%$, e os frascos foram agitados novamente por dois minutos. O material foi filtrado em papel-filtro quantitativo, para tubo Falcon de 50mL. Após a separação das camadas, a superior, metanólica, foi descartada. Do filtrado restante, $10 \mathrm{~mL}$ foram transferidos para béquer com capacidade para $50 \mathrm{~mL}$, com tara prévia. O béquer foi levado para estufa de circulação forçada de ar a $55^{\circ} \mathrm{C}$, para evaporação do solvente, por 24 horas, e, após, foi resfriado em dessecador e pesado. Pela diferença dos pesos do béquer, foi calculado o teor de lipídios da amostra. Para a transesterificação dos triglicerídios, aproximadamente 50mg da matéria lipídica extraída foram transferidos para tubo Falcon de $15 \mathrm{~mL}$, onde foram adicionados $2 \mathrm{~mL}$ de n-heptano. A mistura foi agitada até a completa dissolução da gordura e, então, $2 \mathrm{~mL}$ de $\mathrm{KOH} 2 \mathrm{~mol} / \mathrm{L}$ em metanol foram adicionados. Essa mistura foi agitada vigorosamente por aproximadamente cinco minutos. Após a separação das fases, $1 \mathrm{~mL}$ da fase superior (heptano e ésteres metílicos de ácidos graxos) foi transferido para microfrascos de $1,5 \mathrm{~mL}$. Estes 
foram hermeticamente fechados, protegidos da luz e armazenados em congelador $\left(-18^{\circ} \mathrm{C}\right)$, para posterior análise cromatográfica.

As determinações qualitativas dos ácidos graxos foram feitas por meio de cromatografia gasosa (Shimadzu, modelo GC-14B), em cromatógrafo dotado com detector de ionização de chama (FID), utilizando-se coluna capilar de sílica fundida de $30 \mathrm{~m}$ de comprimento, diâmetro de $0,25 \mathrm{~mm}$ e $0,25 \mu \mathrm{m}$ de espessura do filme (Supelco Omegawax 250). O gás de arraste utilizado foi o hidrogênio, com fluxo ajustado a $1 \mathrm{~mL} /$ minuto. O volume de injeção foi de $1 \mu \mathrm{L}$, com razão "split" de 1:100. A temperatura do forno foi programada para iniciar em $100^{\circ} \mathrm{C}$, permanecendo assim por dois minutos, então levada a $220^{\circ} \mathrm{C}$, à taxa de $4^{\circ} \mathrm{C} /$ minuto, e mantendo-se nessa temperatura por 25 minutos. A temperatura do detector foi de $280^{\circ} \mathrm{C}$ e a do injetor de $250^{\circ} \mathrm{C}$, com o fluxo dos gases de 23 , 50 e $180 \mathrm{kPa}$ para o ar sintético, o hidrogênio e o nitrogênio, respectivamente.
O delineamento utilizado foi inteiramente ao acaso, com quatro tratamentos e sete repetições. As análises de variância foram realizadas adotando-se o PROC GLM. Verificada a significância do teste $\mathrm{F}(\mathrm{P}<0,05)$, as médias dos tratamentos foram comparadas utilizando-se o teste de Tukey a $5 \%$.

Como ferramenta de auxílio às análises estatísticas, foi utilizado o programa SAS, versão 9.1 (Statistical..., 2001)..

\section{RESULTADOS E DISCUSSÃO}

A inclusão de glicerina bruta e ureia não promoveu alterações significativas no consumo de matéria seca, no ganho de peso, na conversão alimentar, no rendimento de carcaça, na área de olho de lombo e na espessura de gordura (P>5\%), (Tab. 2).

Tabela 2. Desempenho e características de carcaça de fêmeas Nelore em terminação

\begin{tabular}{|c|c|c|c|c|c|c|}
\hline \multirow{2}{*}{ Variáveis } & \multicolumn{4}{|c|}{ Tratamentos } & \multirow[b]{2}{*}{$\operatorname{Pr}>\mathrm{F}$} & \multirow[b]{2}{*}{ EPM } \\
\hline & $\mathrm{C}$ & $\mathrm{U}$ & G10 & GU10 & & \\
\hline CMS, kg & 8,92 & 9,76 & 9,28 & 9,49 & 0,49 & 0,23 \\
\hline $\mathrm{GP}, \mathrm{kg}$ & 85,57 & 88,71 & 92,57 & 91,57 & 0,55 & 2,76 \\
\hline GPD, kg & 1,22 & 1,26 & 1,32 & 1,31 & 0,55 & 0,04 \\
\hline EA & 0,13 & 0,12 & 0,14 & 0,13 & 0,34 & 0,67 \\
\hline $\mathrm{RC}, \%$ & 56,26 & 56,62 & 57,43 & 57,48 & 0,38 & 1,23 \\
\hline $\mathrm{AOL}, \mathrm{cm}^{2}$ & 50,68 & 56,1 & 54,96 & 54,89 & 0,52 & 1,37 \\
\hline $\mathrm{EG}, \mathrm{mm}$ & 5,37 & 5,55 & 6,83 & 6,31 & 0,56 & 0,41 \\
\hline
\end{tabular}

$\mathrm{C}=$ tratamento controle, $\mathrm{U}=$ tratamento com ureia, $\mathrm{G} 10=$ tratamento com $10 \%$ de glicerina, GU10 = tratamento com $10 \%$ de glicerina e ureia. $\mathrm{CMS}=$ consumo de matéria seca, GP = ganho de peso, GPD = ganho de peso diário, EA= eficiência alimentar, $\mathrm{RC}=$ rendimento de carcaça, $\mathrm{AOL}=$ área de olho de lombo, $\mathrm{EG}=$ espessura de gordura.

O ganho de peso dos animais foi condizente com as dietas formuladas para fêmeas da raça Nelore confinadas, em média $1,27 \mathrm{~kg} / \mathrm{dia}$, assim como o consumo de matéria seca (Valadares Filho et al., 2006).

Em consonância com Pyatt et al. (2007), Parsons et al. 2009 Mach et al. (2009) e Françozo et al. (2013), quando foram utilizadas dietas com $10 \%$ ou mais de inclusão de glicerina, as dietas não influenciaram o desempenho produtivo nem as características de carcaça e da carne dos animais confinados.
Segundo Luchiari Filho (2000), o rendimento de carcaça quente pode apresentar variação de acordo com o padrão racial dos animais utilizados, o volume ruminal, o tempo de jejum, o transporte e o grau de rigidez do processo de limpeza das carcaças, em que os valores para o rendimento de carcaça quente variam entre $53 \mathrm{e}$ $56 \%$. O rendimento médio encontrado foi de $56,94 \%$, ou seja, está dentro do ótimo esperado para bovinos confinados.

A área de olho de lombo é diretamente relacionada ao índice de musculosidade do 
animal que possui alta herdabilidade genética (Bertrand, 2001). A expressão dessa, por sua vez, é influenciada por fatores externos, tal como a alimentação. As dietas não influenciaram na área de olho de lombo e os animais puderam expressar o seu potencial de produção.

A gordura de cobertura apresenta função de proteção da carcaça dentro da câmara frigorífica, protegendo-a das baixas temperaturas, funcionando como isolante térmico e diminuindo o encurtamento das fibras musculares causado pela queda brusca na temperatura na camada superficial do músculo, o que traz consequências negativas à maciez e à textura da carne (Jorge et al., 2008). Em muitos frigoríficos o produtor é remunerado de acordo com a espessura de gordura subcutânea; o ideal varia de 3 a $6 \mathrm{~mm}$. No presente experimento, as novilhas apresentaram média de $6,01 \mathrm{~mm}$. A espessura de gordura não foi modificada pela inclusão de glicerina bruta e ureia, portanto as dietas não interferiram no grau de acabamento dos animais.

A glicerina bruta, associada à ureia ou não, não teve influência quanto à composição físicoquímica da carne (Tab. 3).

Segundo Felício (1997), o aumento da gordura na carcaça faz com que a queda da temperatura interna durante o resfriamento seja mais lenta, favorecendo a ação de enzimas do tipo calpaínas, que deixam a carne mais macia. A idade de abate também pode interferir na maciez da carne, pois animais mais velhos possuem a carne mais dura devido ao aumento do tecido conjuntivo no músculo. Como os animais eram contemporâneos, provenientes do mesmo lote e manejo, o grau de acabamento é que poderia influenciar na maciez. Como a espessura de gordura não apresentou diferença significativa $(\mathrm{P}>0,05)$, a maciez, medida por meio de forca de cisalhamento, teve o mesmo comportamento.

Tabela 3. Características físico-químicas da carne de novilhas Nelore em terminação

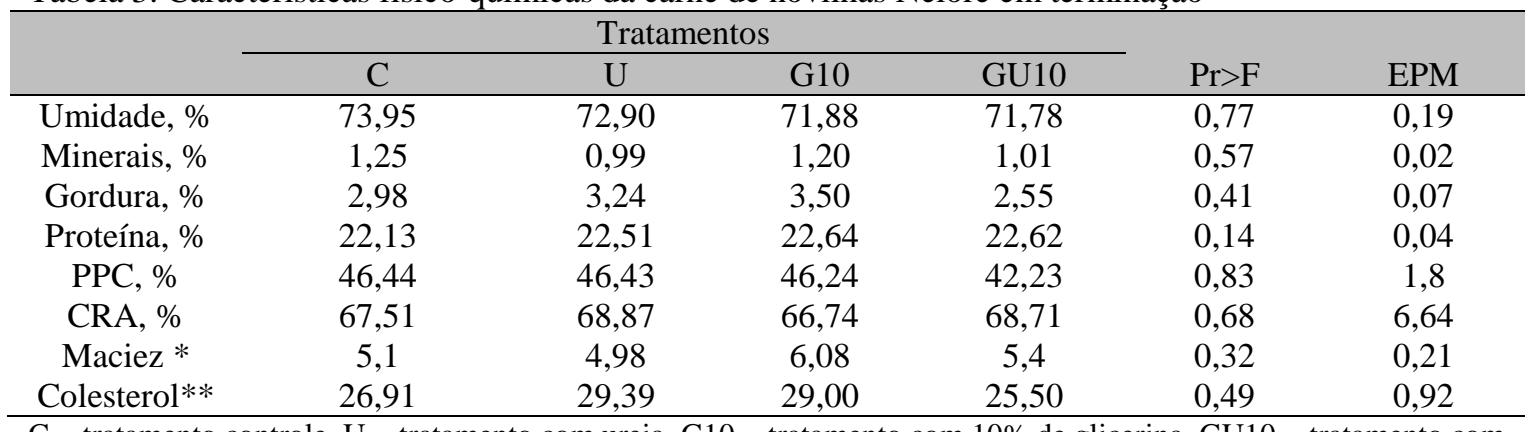

$\mathrm{C}=$ tratamento controle, $\mathrm{U}=$ tratamento com ureia, $\mathrm{G} 10=$ tratamento com $10 \%$ de glicerina, GU10 = tratamento com $10 \%$ de glicerina e ureia. $\mathrm{PPC}=$ perdas por cocção, CRA = capacidade de retenção de água. $* \mathrm{Kgf} / \mathrm{cm}^{2} * * \mathrm{mg} / 100 \mathrm{~g}$.

O valor médio de maciez foi de $5,39 \mathrm{kgf} / \mathrm{cm}^{2}$, o que, para alguns autores, pode ser considerado como uma carne dura, devido a fatores relacionados com a análise (Poste et al., 1993) e o equipamento utilizado (Pinto et al., 2010), que podem gerar diferentes valores de força de cisalhamento, fazendo com que ocorram diferenças entre a carne macia e a dura de acordo com o autor referência, o que prejudica a interpretação dos dados. Assim, autores estabelecem diferentes limites entre a carne macia e a dura; Pazdiora (2011) e Mckeith et al. (1985) citam 4,5kg; Johnson et al. (1990), 5,5kg; e Felício (1999), 5kg.

Segundo Lawrie (2004), a carne bovina possui, em média, o teor de colesterol de $59 \mathrm{mg} / 100 \mathrm{~g}$. No presente experimento, foram observados valores médios de $27,7 \mathrm{mg} / 100 \mathrm{~g}$ de colesterol na carne, $53 \%$ abaixo da média proposta por Lawrie (2004), e, assim, novilhas da raça Nelore terminadas com as dietas utilizadas neste experimento podem contribuir para aumentar a qualidade da carne, diminuindo o teor de colesterol, o que contribui para produção de carne mais saudável.

Gorduras insaturadas ingeridas pelos ruminantes sofrem o processo de bio-hidrogenação no rúmen, sendo transformadas em outros tipos de gordura. A bio-hidrogenação altera o tipo de gordura que chega ao intestino para ser absorvida (Kozloski, 2009). Uma forma de diminuir o efeito da bio-hidrogenação é aumentando a taxa 
de passagem, por exemplo, aumentando a inclusão de concentrado na dieta ou diminuindo a fibra da dieta (Van Soest, 1994). Com a inclusão de glicerina na dieta, aumenta-se o aporte energético sem incluir fibra à dieta e pode-se aumentar a taxa de passagem, bem como a produção de propionato, reduzindo o hidrogênio livre no rúmen.

A utilização de ureia ou de glicerina bruta não alterou o perfil de ácidos graxos da carne, ao nível de 5\% de significância (Tab. 4).

O consumo de gordura saturada proveniente da carne bovina é associado ao aumento nos teores de LDL sanguíneo, a qual está relacionada com o aumento de doenças cardiovasculares em humanos. Por outro lado, foi demonstrado que produtos derivados de ruminantes podem ser fonte natural de ácido linoleico, que possui inúmeras funções fisiológicas interessantes para a saúde humana, como efeito anticarcinogênico, redução da deposição de gordura, auxílio no controle da diabetes, aumento na deposição de massa muscular e aumento na mineralização óssea.

Estudos apontam que a glicerina pode alterar a qualidade do perfil de ácidos graxos. Eiras et al. (2014) avaliaram as características de carcaça e da carne de novilhos jovens terminados em confinamento recebendo dietas com $0,6,12$ e $18 \%$ de glicerina na matéria seca da dieta. A inclusão de glicerina teve efeito sobre o perfil de ácidos graxos $(\mathrm{P}<0,01)$, ocorreu diminuição de ácidos graxos saturados e aumento nos ácidos graxos mono e poli-insaturados.

No presente estudo, nas concentrações totais de ácidos graxos saturados, insaturados, poliinsaturados e na relação insaturados/saturados de gordura de cobertura, também não houve efeito $(\mathrm{P}>0,05)$ da inclusão de glicerina, indicando que, apesar de a glicerina alterar a forma de obtenção de energia, não alterou o perfil dos ácidos graxos da carne.

De forma geral, as dietas foram eficientes para a categoria animal utilizada, que pôde expressar seu potencial genético, pois em todos os parâmetros avaliados apresentou-se de forma adequada e satisfatória, com ótimo desempenho e produção de carne de qualidade.

Portanto, a associação da glicerina bruta com a ureia é mais uma alternativa viável para utilização em sistemas de produção de bovinos confinados cujo custo com alimentação pode chegar a $75 \%$ dos custos totais do confinamento.

Tabela 4. Perfil dos principais ácidos graxos da carne (\%) de novilhas Nelore em terminação

\begin{tabular}{|c|c|c|c|c|c|c|}
\hline & \multicolumn{4}{|c|}{ Tratamentos } & \multirow[b]{2}{*}{$\operatorname{Pr}>F$} & \multirow[b]{2}{*}{ EPM } \\
\hline & $\mathrm{C}$ & $\mathrm{U}$ & G10 & GU10 & & \\
\hline Mirístico & 3,07 & 3,09 & 3,23 & 3,15 & 0,93 & 0,09 \\
\hline Palmítico & 26,83 & 25,68 & 27,30 & 25,97 & 0,11 & 0,23 \\
\hline Palmitoleico & 3,13 & 3,37 & 3,46 & 3,18 & 0,50 & 0,07 \\
\hline Esteárico & 16,03 & 14,14 & 13,92 & 14,97 & 0,14 & 0,31 \\
\hline Oleico & 41,61 & 43,06 & 41,90 & 41,63 & 0,55 & 0,37 \\
\hline Cisvacênico & 1,90 & 2,09 & 1,87 & 1,81 & 0,21 & 0,04 \\
\hline Linoleico & 2,99 & 3,68 & 2,57 & 3,08 & 0,36 & 0,19 \\
\hline Saturados & 45,93 & 42,91 & 44,45 & 44,09 & 0,62 & 1,4 \\
\hline Insaturados & 54,07 & 57,09 & 55,55 & 55,91 & 0,32 & 0,97 \\
\hline Poli-insaturdos & 3,98 & 4,78 & 3,48 & 4,12 & 0,14 & 0,34 \\
\hline $\mathrm{I} / \mathrm{S}$ & 1,18 & 1,33 & 1,25 & 1,27 & 0,47 & 0,03 \\
\hline
\end{tabular}

\section{CONCLUSÃO}

A glicerina bruta associada à ureia é uma alternativa viável para terminação de novilhas da raça Nelore em confinamento, uma vez que não prejudica o consumo, o desempenho e principalmente as características da carne. 


\section{REFERÊNCIAS}

AL-HASANI, S. M.; HLAVAC, J.; CARPENTER, M.W. Rapid determination of cholesterol in single and multicomponent prepared foods. J. Assoc. Off. Anal. Chem. Int., v.76, p.902-906, 1993.

BERTRAND, J.K.; GREEN, R.D.; HERRING, W.O. et al. Genetic evaluation for beef carcass traits. $J$. Anim. Sci., v.9, Suppl., p.190-200, 2001.

BLIGH, E.G.; DYER, N.J. A rapid method of total lipid extration and purification. J. Biochem. Physiol., v.37, p.911-917, 1959

DONKIN, S.S. Glicerol from biodiesel production: the new corn for dairy cattle. Braz. J. Anim. Sci., v.37, Suppl., p.280-286, 2008.

EIRAS, C.E.; MARQUES, J.A.; PRADO, R.M. et al. Glycerine levels in the diets of crossbred bulls finished in feedlot: carcass characteristics and meat quality. Meat Sci., v.96, p.930-936, 2014.

FELÍCIO, P.E. Carne de touro jovem. Rev. Nac. Carne, v.21, p.91-92, 1997.

FELÍCIO, P.E. Qualidade da carne bovina: características físicas e organolépticas. In: REUNIÃO ANUAL DA SOCIEDADE BRASILEIRA DE ZOOTECNIA, 36., 1999, Porto Alegre. Anais... Porto Alegre: Sociedade Brasileira de Zootecnia, 1999. [11p.].

FRANÇOZO, M.C.; PRADO, I.N.; CECATO, U. et al. Growth performance, carcass characteristics and meat quality of finishing bulls fed crude glycerinsupplemented diets. Braz. Arch. Biol. Technol., v.56, p.327-336, 2013.

GONÇALVES, V. L. C.; PINTO, B. P.; SILVA, J. C. et al. Acetylation of glycerol catalyzed by different solid acids. Cat. Tod., v.1 p.133-135, 2008.

HAMM, R. Biochemistry of meat hidratation. $A d v$. Food Res., v.10, p.335-443, 1960.

HONIKEL, K.O. Reference methods for the assessment of physical characteristics of meat. Meat Sci., v.49, p.447-457, 1998.

JOHNSON, D.D.; HUFFMAN, R.D.; WILLIAMS, S.E. et al. Effect of percentage Brahman and Angus breeding age-season of feeding and slaughter end point on meat palatability and muscle characteristics. J. Anim. Sci., v.68, p.1980-1986, 1990.

JORGE, A.M.; FONTES, C.A.; PAULINO, MF. et al. Desempenho produtivo de animais de quarto raças zebuínas, abatidas em três estágios de maturidade. Rev. Bras. Zootec., v.37, p.350-357, 2008.
KOZLOSKI, V.G. Bioquímica dos ruminantes. 2.ed. Santa Maria: UFSM, 2009. 216p.

LAWRIE, R.A. Ciência da carne. 6.ed. Porto Alegre: Artmed, 2004. 384p.

LUCHIARI FILHO, A. Pecuária da carne bovina. São Paulo: LinBife, 2000. 134p.

MACH, N.; BACH, A.; DEVANT, D. Effects of crude glycerin supplementation on performance and meat quality of Holstein bulls fed high-concentrate diets. J. Anim. Sci., v.87, p.632-638, 2009.

MCKEITH, F.K.; DEVOL, D.L.; MILES, R.S. et al. Chemical and sensory properties of thirteen major beef muscle. J. Anim. Sci., v.50, p.869-872, 1985.

PARSONS, G.L.; SHELOR, M.K.; DROUILLARD, J.S. Performance and carcass traitsbof finishing heifers fed crude glycerin. J. Anim. Sci., v.87, p.653-657, 2009.

PAZDIORA R.D. Pesos de abate e ureia protegida na dieta de terminação em confinamento de bovinos Nelore não castrados. 2011. 125f. Tese (Doutorado em Zootecnia) - Faculdade de Ciências Agrárias e Veterinárias. Universidade Estadual Paulista "Júlio de Mesquita Filho, Jaboticabal, SP.

PINTO, M.F.; PANSANO, E.H.G.; ALMEIDA, A.P.S. Espessura da lâmina decisalhamento na avaliação instrumental da textura da carne. Ciênc. Rural, v.40, p.1405-1410, 2010.

POSTE, L.; BUTLER, G.; MACKIE, D. et al. Correlations of sensory and instrumental meat tenderness value as affected by sampling techniques. Food Qual. Prefer., v.4, p.207-214, 1993.

PYATT, N.A.; DOANE, P.H.; CECAVA, M.J. Effect of crude glycerin in finishing cattle diets. J. Anim. Sci., v.85, Suppl.1, p.553, 2007.

STATISTICAL analysis system user's guide. Version 9.1. Cary: SAS, 2001.

SCHRÖDER, A; SÜDEKUM, K.H. Glycerol as a byproduct of biodiesel production in diets for ruminants. In: INTERNATIONAL RAPESEED CONGRESS, 10., 1999, Canberra. Proceedings... Canberra: Regional Institute, 1999. 241 p.

VALADARES FILHO, S.C.; MAGALHÃES, K.A.; ROCHA JÚNIOR. et al. Tabelas brasileiras de composição de alimentos para bovinos. 2.ed. Viçosa, MG: Universidade Federal de Viçosa, 2006. 329p.

VAN SOEST, P.J. Nutrition ecology of the ruminants. Ithaca: Cornell University Press, 1994. 476 p. 